\title{
Doing things together: adolescent health and family rituals
}

\author{
E Compañ, J Moreno, M T Ruiz, E Pascual
}

See end of article for authors' affiliations

Correspondence to Elena Compañ Poveda, Unidad de Atención a la Familia, Centro Dr

Esquerdo, Diputación de Alicante, Spain; ecompañ@dip-alicante.es

Accepted for publication 12 July 2001
Study objectives: (1) To describe the union and life cycle of family rituals, such as specific habits of sharing daily meals, special events or other family activities, and (2) to analyse the relation between the practice of family rituals and the use by adolescents of mental health related ambulatory care services.

Design: A cross sectional study.

Setting: A public mental health care outpatient clinic, secondary educational centres and Alicante University (School of Social Workers and Nursing School) in Spain.

Participants: A total of 282 living at home youngsters were included in the study. The case group, $n=82$, was sequential and consecutively drawn from the first consultation in a public mental health outpatient clinic attending a downtown area of Alicante. The comparison group $(n=213)$ was made up of a conglomerate from various educational centres in the same metropolitan area.

Main results: There was a significant difference $(p=0.027)$ between the frequencies with which parents ate together with their offspring in the two study groups. The families of the adolescents comparison group significantly $(p=0.00007)$ shared more family celebrations than the case group-also, the extended family was included more frequently. Moreover, differences between both groups were found in other activities and situations-adolescents in the case group reported carrying out less family activities than the adolescents in the comparison group $(p=0.00001)$. The lower level of satisfaction in the adolescent's perception of family function led to a higher probability of presenting mental health complaints $(p=0.00001)$.

Conclusions: The youngsters with mental health complaints ate less frequently with both parents than the youngsters in the comparison group. They also shared less activities and practised less family rituals - union and life cycle-than the families of the youngsters in the comparison group, and showed a lower level of satisfaction in perceived family function.
$\Lambda^{s}$ daily health risks in the family environment have been considered thus far innocuous, and the ability to cope with them has been commonly assumed, little effort has been made in epidemiological research to deepen our understanding of this basic social unit, the family. Moreover, a strong tendency in epidemiology to focus on the individual may also have contributed to this fact. However, the new trends in epidemiology and public health give more emphasis to the analysis of systems and the way they relate to the individual, and vice versa. ${ }^{1}$ This paper analyses the family as a system in relation to health complaints.

As social conditions influence individual life style through the family structure and its dynamics, the analysis of the family system should be considered a useful tool in public health to monitor social related health problems.

The General Theory of Systems have described the family as an open system of individuals embodying a bio-psycho-social unit, which, in constant evolution, develops its own history and living patterns. ${ }^{2}$ In this sense, distress of a single member of this unit can be considered as a symptom of family malfunction. Besides, immersed in a broader social environmental net, the family carries out a constant exchange of information and feedback, where adaptation to social change becomes the key issue for the family's growth and survival. This adaptation is achieved through a self regulation process, where either existing rules are reinforced or new rules are created to insure healthy family function..$^{2-4}$

At the same time, this self regulation process is successful when the following competing forces balance properly: (1) Homeostatic forces, which keep stasis, and (2) Morfogenetic forces, which generate new situations and resources as well as facilitate the change. ${ }^{235}$

However, on the one hand, some of the family systems are so strict that they become paralysed when changes occur: unable to create new rules to solve new conflicts, they continue to rely on what had worked in the past, but no longer functions. On the other hand, a family system that is too permissive confronts change in such an anarchic way that the result is once again dysfunctional. ${ }^{346}$ The first results from abusing homeostatic forces, while the second follows the misuse of morfogenetic forces.

Since the early 1970s, rituals have been used in the clinical field to increase family cohesion, strengthen the individual sense of identity and promote changes at a family level. ${ }^{7-11}$ At first, rituals were observed by anthropologists in religious contexts, but, later on, they were also observed in secular contexts. Rituals have been described as a series of repetitive, symbolic and sequential acts, which are performed by a group and passed on from generation to generation; not only behavioural rules, traditions and beliefs, but also the important events in the life of an individual or the group as a whole. $^{78}{ }^{12-14}$

At the family level, rituals show the degree of cohesion existing among family members, as well as the rules and patterns that they follow relating to each other. In the same way the disorganisation of the family system is also related to the practice of rituals because of the absence of cohesion and rules. At the individual level, rituals play a significant part all the way through psychological growth and development. ${ }^{10}{ }^{12-15}$ This is one of the important reasons why rituals have been used by professionals in the family field as a principal diagnostic and therapeutic resource in their work with dysfunctional families. ${ }^{711} 1617$

Since the dawn of time, the dining table has been the nexus of familial interaction. The simple act of sharing meals solidifies the family's identity by modelling a wide range of learned behavioural patterns. One of the groups most affected in this 
Table 1 Main characteristics of youngsters and their families

\begin{tabular}{|c|c|c|c|}
\hline Sociodemographic characteristics & Cases & Non-cases & \\
\hline Number & 82 & 177 & \\
\hline Age (mean (SD)) & $18.4(2.4)$ & $17.8(2.5)$ & NS \\
\hline Sex (male) & $45.4 \%$ & $40.2 \%$ & NS \\
\hline Family members (frequency) & $4.6(1.4)$ & $4.6(1.1)$ & NS \\
\hline Other members leaving with the family & $1.2(1.4)$ & $0.9 \pm 0.9$ & NS \\
\hline Father's occupational status & $\mathrm{n}=72$ & $n=166$ & \\
\hline Employed & $81.9 \%$ & $91.6 \%$ & $p=0.03$ \\
\hline Domestic work & $1.4 \%$ & & \\
\hline Retired & $11.1 \%$ & $3 \%$ & \\
\hline Unemployed & $5.6 \%$ & $5.4 \%$ & \\
\hline \multicolumn{4}{|l|}{ Mother's occupational status } \\
\hline Employed & $42.7 \%$ & $36.7 \%$ & NS \\
\hline \multicolumn{4}{|l|}{ Father's education level } \\
\hline Less than Primary school & $21.1 \%$ & $17 \%$ & \\
\hline Secondary school & $64.8 \%$ & $65.9 \%$ & NS \\
\hline University school & $14.1 \%$ & 17.1 & \\
\hline \multicolumn{4}{|l|}{ Mother's education level } \\
\hline Less than Primary school & $15 \%$ & $22.1 \%$ & \\
\hline Secondary school & $73.7 \%$ & $63.9 \%$ & NS \\
\hline University school & $11.3 \%$ & $14 \%$ & \\
\hline
\end{tabular}

sense are adolescents. Thus, the ritual of the shared meal continuously reinforces individual identity: who he/she is, where does he/she belong or which his/her role might be. ${ }^{91516}{ }^{18}$ This is why it is considered a homeostatic ritual. ${ }^{90}$

There is evidence derived from longitudinal studies based on social and biological information that suggests a relation between adolescent development and health problems. ${ }^{19} 20$ Unfortunately, studies on the relation between adolescent health and family rituals are scarce. There are some studies that examine the connection between adolescents' behaviour and family rituals. For instance, the results of a study about the use of health services by adolescents showed that of the group with the highest need for services, $77 \%$ had the perception of family dysfunction. ${ }^{21-25}$

The hypothesis of this study is that there exists a connection between the practice of family rituals and adolescent mental health. Therefore, the aim of the study is twofold: firstly, to describe the union and life cycle rituals, such as the sharing of daily meals as well as special events and other family activities. Secondly, to analyse the connection between the practice of family rituals and the use by adolescents of mental health related ambulatory care services.

\section{METHODS}

A cross sectional study was designed to obtain-through a structured anonymous questionnaire-individual and family data based on the perception of 14 to 23 year old adolescents. We chose this rank, for it coincided with the age when more than one half of the youngsters still lives with their parents and not only depends economically on them, but also in terms of psychological growth and development. It is important to

\begin{tabular}{|c|c|c|}
\hline & Cases (\%) & Non-cases (\%) \\
\hline Number & 82 & 177 \\
\hline Nuclear family & 26.8 & 45.5 \\
\hline Numerous nuclear family & 34.1 & 27.3 \\
\hline Enlarged nuclear family & 17.1 & 17.6 \\
\hline Extended family & 3.7 & 0.6 \\
\hline Binuclear family & 4.9 & 1.7 \\
\hline Single parent family & 12.2 & 6.8 \\
\hline Others & 1.2 & 0.6 \\
\hline
\end{tabular}

mention that no member of the family has influenced on adolescents when responding the questionnaires.

A total of 282 youngsters who lived at home were included in the study. The case group, $\mathrm{n}=82$, was sequential and consecutively drawn from first consultations with patients attending a public mental health outpatient clinic in the downtown area of Alicante (around 100000 residential population). Fifty seven per cent were $\leqslant 18$ years and $43 \%$ between 19 years and 23 years. Patients had been referred to the clinic through general practitioners in the area, either by clinical judgement or at the patients' request. The most frequent complaints were anxiety and depression. The exclusion criteria were based on the presence of cognitive problems when filling out the questionnaire and on a residence status outside the family.

As adolescents in general tend to exhibit a high degree of psychological stress, we felt that we needed to select an objective criteria to identify those individuals who were suffering from true emotional dysfunction. We chose as our study group those adolescents who had, of their own volition, sought assistance from health services. We assumed that those youngsters who continued to attend school, while possibly suffering from some emotional distress, were not so debilitated that they could not lead a normal life. The study group, however, had at some point reached a level of dysfunction, which they felt required outside intervention to overcome. Thus, the comparison group $(n=213)$ was obtained by conglomerates from educational centres- $55 \% \leqslant 18$ years from one secondary school centre and $45 \%$ between 19 and 23 year old from social work and nursing schools at the university-in the same metropolitan area. Therefore, given the fact that the public health system has universal coverage, in the event that the adolescents of the comparison group fell ill, they would be attended to by the same health clinic. Youngsters who admitted to having previously contacted mental health specialists $(n=23)$ were excluded from the study. At the same time, 13 incomplete questionnaires were dropped out of the study. The final sample was composed of 82 cases and 177 non-cases.

To avoid the recall bias, a questionnaire asking about current family habits was developed. This questionnaire gathered the following information:

(1) Personal and family data (age, gender, number of family members living together, outside members living with the family and occupational and educational level of both parents). 


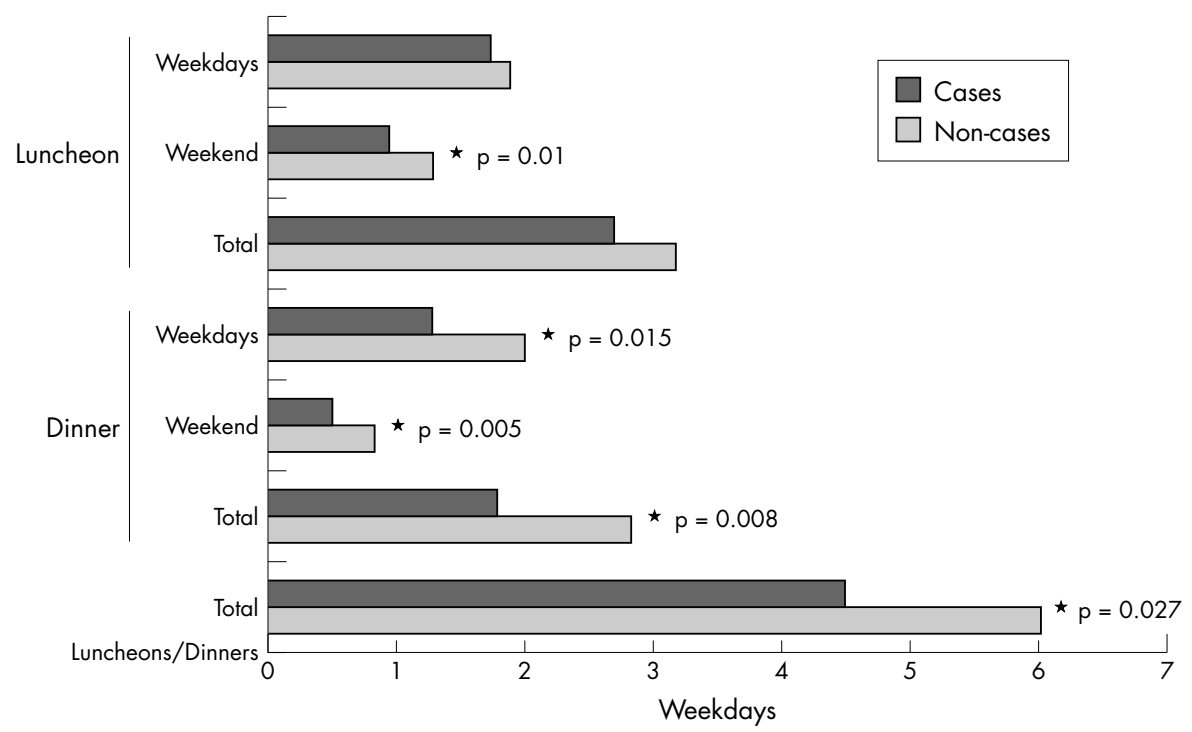

Figure 1 Mean frequency by week of daily meals shared with both parents.

(2) Family typology (nuclear family, numerous nuclear family, enlarged nuclear family, extended family, binuclear family, single parent family and others $).{ }^{26}$

(3) Family rituals:

- union rituals (homeostatic function), such as sharing meals with any member of the family at daily meals, as well as sharing with nuclear or extended family to celebrate special events, such as Christmas, Easter, Father's/ Mother's Day. In order to study the variables related to the habits of sharing meals with the family, local customs, such as getting together at lunch time (from 2-3 pm) or at dinner time (from 9-10 pm), were taken into account. The following response categories were considered, as well:

- (a) Adolescents sharing meals (lunch and/or dinner) with both parents (yes/no).

- (b) Adolescents sharing meals (lunch and/or dinner) with only one parent (yes/no)

- (c) Sharing meals with none of the parents (yes/no).

- life cycle rituals (morfogenetic function), such as celebrating (yes/no) with the nuclear family and/or extended family special events, say, birthdays, anniversaries and welcome/farewell parties. ${ }^{89}$

(4) Other activities which could gather the family together (yes/no): parties, holidays, trips, shows, movies, shopping, sports activities, table games, TV and family discussions, walks and homework and others. ${ }^{12}$
(5) An "APGAR Family Questionnaire" was administered to test perceived family dysfunction. There was evidence to support the use of the APGAR Family Questionnaire as a reliable, validated, utilitarian instrument to measure a subject's level of satisfaction with five components of family function. ${ }^{27}{ }^{28}$ This is a self administered item questionnaire where the subject is asked to express his/her degree of agreement with each statement, using a three point frequency scale $(0=$ rarely, $\mathrm{l}=$ sometimes, $2=$ often). This questionnaire gathers information on the following variables:

I Satisfaction with the support received from the family.

II Satisfaction with the family agreement process.

III Perception of family acceptance and support of wishes. IV Feelings of being loved by the family.

V Satisfaction with the amount of time spent with the family.

Scores totalling 7-10 indicate normal family function; 4-6 show some degree of dysfunction and $0-3$ indicate severe dysfunction.

A pre-test $(n=20)$ was performed to determine the presence of possible problems, the feasibility of the study as well as the operability of the questionnaire.

The statistical treatment of results was calculated using SPSS v.7.5 for Windows with 95\% confidence levels for parameter estimation. In order to establish comparison groups, the following tests were used: (1) for qualitative variables, the Pearson's $\chi^{2} ;(2)$ for quantitative variables, Student's

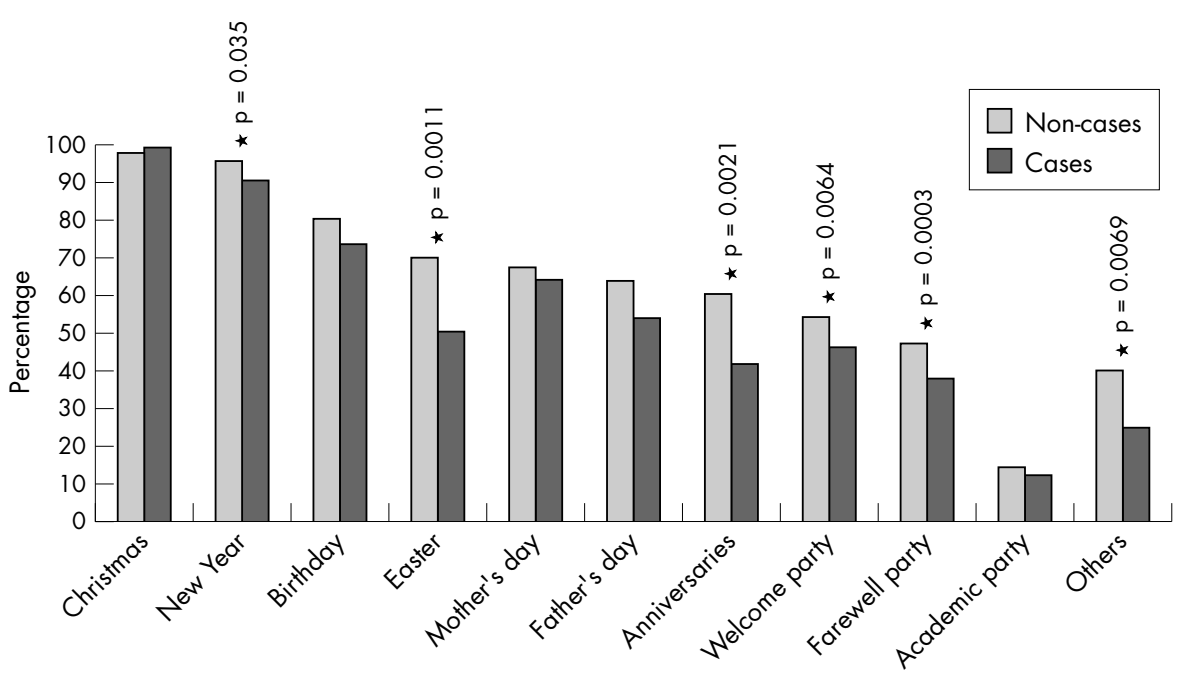

Figure 2 Main family celebrations. 


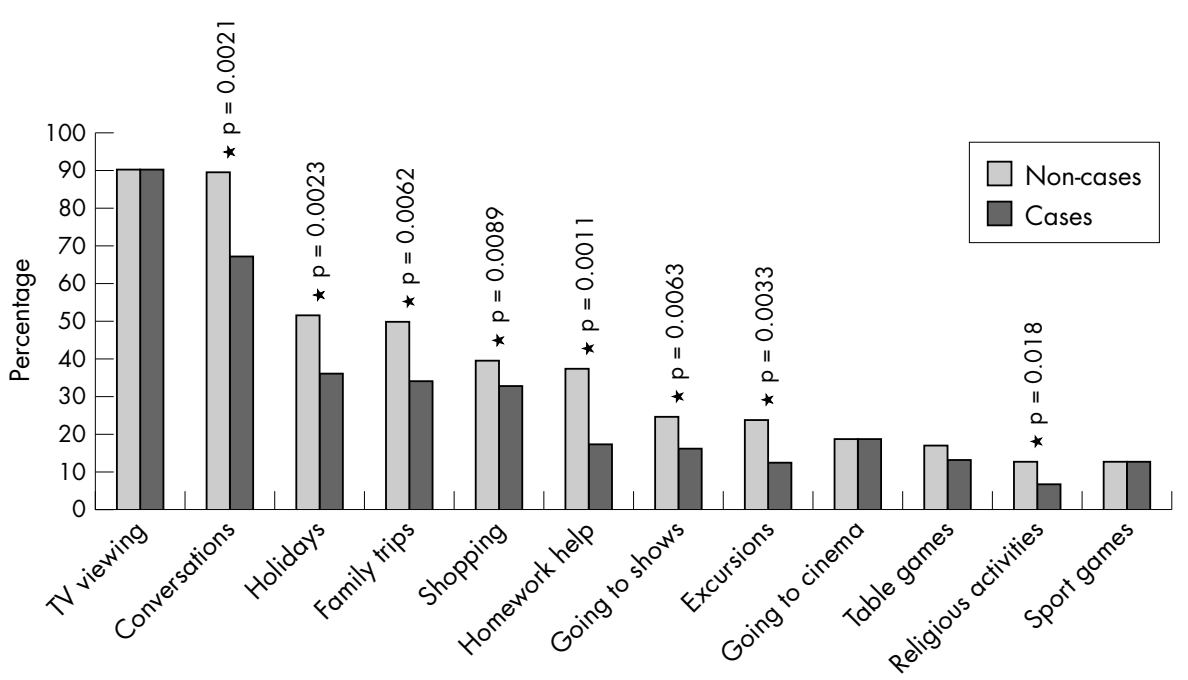

Figure 3 Family activities.

$t$ test and one way analysis of variance; and (3) for ordinal variables, the Mann-Whitney U test.

\section{RESULTS}

Table 1 shows sociodemographic characteristics for both groups. No significant differences were detected with regard to age, sex, family size, education level of both parents, inclusion of extended family members and mother's employment status. These are the principal variables that could influence the behaviour of the studied variables: the relation between family rituals-activities and APGAR, and the request for professional help.

Table 2 shows the distribution of the family typology for each of the groups. As can be seen, a greater number of single parent family, binuclear or extended exists in the case group $(\mathrm{p}=0.02)$.

Figure 1 shows a significant difference $(p=0.027)$ concerning the frequency with which parents shared meals with their offspring in the two study groups. Out of a possible total of 14 weekly meals, the case group ate together an average of 4.49
(95\% CI 3.31 to 5.59 ), while the comparison group ate an average of 6.02 (95\% CI 5.26 to 6.78 ) meals together. The case group tended to miss weekday dinners and both lunch and dinner on the weekends, thus explaining the disparity between the two groups. Namely, the families of the study case group appeared to have had lunch separately $13.9 \%$ (95\% CI $10.1 \%$ to $17.7 \%$ ) of the time, while the percentage of families who ate apart in the comparison group decreased to $4.5 \%$ (95\% CI $1.5 \%$ to $7.6 \%)(p=0.008)$. Regarding dinner, the families of the case group ate apart $32.9 \%$ (95\% CI $22.5 \%$ to $43.3 \%)$ of the time, while the percentage also decreased to $17.5 \%$ (95\% CI $11.9 \%$ to $23.1 \%)(\mathrm{p}=0.006)$ of the comparison group.

As figure 2 shows, the families of the comparison group not only got together more frequently than the case group for special events, such as New Year's Day, Easter, welcome/farewell parties $(p=0.00007)$, but they also included the extended family more frequently in these celebrations.

Differences between both groups of families were also found with regard to other activities (fig 3). Adolescents in the

Table 3 Youngsters perception of family dysfunction in percentages

\begin{tabular}{|c|c|c|c|c|}
\hline Family APGAR & Scale* & Cases $(\%)$ & Non-cases (\%) & \\
\hline Number & & 82 & 177 & \\
\hline \multirow[t]{3}{*}{ Satisfaction with the support received from the family } & 0 & 20.7 & 6.9 & \multirow{3}{*}{$p=0.00001$} \\
\hline & 1 & 40.2 & 24.9 & \\
\hline & 2 & 39.1 & 68.2 & \\
\hline \multirow[t]{3}{*}{ Satisfaction with the family agreement process } & 0 & 42.7 & 19.7 & \multirow{3}{*}{$p=0.00001$} \\
\hline & 1 & 46.3 & 38.2 & \\
\hline & 2 & 11 & 42.1 & \\
\hline \multirow[t]{3}{*}{ Perception of family acceptance and support of wishes } & 0 & 25.6 & 4.6 & \multirow{3}{*}{$p=0.00001$} \\
\hline & 1 & 39 & 37 & \\
\hline & 2 & 35.4 & 58.4 & \\
\hline \multirow[t]{3}{*}{ Feelings of being loved by the family } & 0 & 3.7 & 1.7 & \multirow{3}{*}{$p=0.03$} \\
\hline & 1 & 20.7 & 12.2 & \\
\hline & 2 & 75.6 & 86.1 & \\
\hline \multirow[t]{3}{*}{ Satisfaction with the amount of time spent with the family } & 0 & 18.3 & 11.6 & \multirow{3}{*}{$p=0.01$} \\
\hline & 1 & 42.7 & 32.3 & \\
\hline & 2 & 39 & 56.1 & \\
\hline \multicolumn{5}{|l|}{ APGAR values } \\
\hline Severe dysfunction & $0-3$ & 19.5 & 6.3 & \multirow{3}{*}{$p=0.00001$} \\
\hline Light dysfunction & $4-6$ & 34.2 & 19.1 & \\
\hline Functional & $7-10$ & 46.3 & 74.6 & \\
\hline
\end{tabular}


comparison group reported participating in more family activities-travelling, excursions, attending parties, shows and church, engaging conversations and helping with school work - than the adolescents in the case group $(\mathrm{p}=0.00001)$.

Regarding the perception of family dysfunction, results are shown in table 3. The case group's lower score values show a higher frequency of perceived family dysfunction, whereas the global scores indicate that $53.7 \%$ (95\% CI $42.9 \%$ to $64.5 \%$ ) of the case group perceived some dysfunction and $19.5 \%$ (95\% CI $10.9 \%$ to $31.8 \%$ ) perceived severe dysfunction; the comparison group showed less than half the level of perceived dysfunction, $25.4 \%$ (95\% CI $19 \%$ to $31.8 \%$ ) and only $6.3 \%$ of severe family dysfunction.

\section{DISCUSSION}

The results show that the families of adolescents with psychological problems practise fewer unifying and life cycle rituals, and share fewer activities than the comparison group. The former cohabitate more separately than the latter, with the resultant risk that their affective relationship might become impoverished. As compared with the study group, the comparison group seems better able to overcome those obstacles that impede daily family interaction: they travel more frequently and celebrate together those events that regulate and solidify affective distance among family members.

Although we have asked about the most common habits in the family life of the participants, the cross sectional nature of the study prevents us from identifying not only the trend of those customs, but also the changes that may have taken place at any given point. These changes are relevant, for they could provide information about the events that make the families self regulate. Therefore, it is highly important to clarify that this is not a causality study and that the cause and effect continuum could run in either direction. In this sense, it is possible, for example, that an eating disorder might act as an independent variable explaining why an adolescent eats with his family less frequently. Conversely adolescent's eating disorder may affect family interaction patterns, which may as well affect the adolescent. However, the number of cases with this symptomatology in the study were of little relevance: three cases of bulimia; one of anorexia and one case of diabetes who ate sweets voluntarily.

It has been observed that the number of retired parents is higher in the case group than in the comparison group. It would be interesting to further explore the study of this information using a larger sample-take for instance, the analysis of the reason for retirement - to find out why this group, who, theoretically, would have plenty of time to devote to their family, implement less unifying and life cycle rituals than any other group. In this study, the percentage of parents, who were retirees, housewives or unemployed, is so small than a more complex analysis could lose statistical validity. Also, no significant differences were found in the stratified analysis comparing the employment status of the parents-retired or active-and the behaviour of the principal variables, namely unifying and life cycle rituals and the adolescents perception of family dysfunction.

Single families may not be able to have regular meals with their children. None the less, this should not have an effect on the increase of emotional disorders if they shared other rituals or activities. Moreover, the absence of one of both parents could influence the patterns of family functioning, but this change does not necessarily have to be dysfunctional. In any case, as can be seen in table 2, the number of single families in our study precludes us from doing multivariate analysis to quantify the existence of differences related to the adolescent sought of professional help across family typology.

Although we have been able to identify the risks that are run when deficiencies exist in life cycle rituals and family interaction, we have not clarified the possible risks that may

\section{Key points}

- Sharing daily meals with the family constitutes a union ritual that promotes adolescent mental health.

- Youngsters who demand health care in mental health services perform less life cycle rituals with their families than other youngsters from the community.

- The decrease in family activities that improve adolescent family communication and emotional closeness, is related to a most frequent use of mental health services.

- The lower level of satisfaction in an adolescent's perception of family function, the higher the probability of evidencing mental health complaints.

result from an excess of such activities. This is due partly to the paucity of information concerning what constitutes normalcy in the realisation of family rituals, above all, as functions of the age of the participants and the frequency of the activities.

As we have already mentioned in the Methods section, given the high rate of psychological disorders existing in adolescents who do not seek for professional services, it is possible that they have not been detected in the comparison group through the selection criteria. None the less, if these disorders had been detected and eliminated, the results would even have raised the differences between the adolescents groups of this study.

The findings should be interpreted in the sociocultural context of a urban area in Spain; an area that has been led to modify its traditional way of life. Social advances that have occurred throughout the 20th century have led to modifications of the traditional way of life. ${ }^{25}$ The industrial revolution as well as women's entry into the occupational world and the resultant increase in commuting time have forced families to work out alternative methods to maintain strong family's relationships. ${ }^{29}$ Besides, given that the vast majority of adolescents in both groups were middle class students, results can only be applicable to youngsters in a similar situation. Nevertheless, it is surprising to verify how the practice of lunch, which was the most practised unifying ritual, has been decreased remarkably. Social changes and the modern way of life seem to have made the practice increasingly difficult. However, a more detailed study of the data has showed us that, despite the fact that both groups eat less frequently together, the families of the case group do it even less frequently than the comparison group. This second group not only ate the midday meal together more frequently, but shared more midweek and weekend dinners, as well.

It is also important to note that the regularity with which the adolescents who requested health service assistance ate with both parents is significantly less, with respect to the comparison group. The relationship between both parents and the child is necessary to facilitate the process of maturation. ${ }^{30}$ Even in single parent families, a child has an implicit contractual relationship with both mother and father. Although the child may prefer one parent to the other, both play an important part in the child's emotional development. ${ }^{31}$ What is perhaps most deceptive are those cases in which both parents are present, and yet the child relates to only one of them, thus jeopardising the normal course of emotional development. ${ }^{32}$

Union rituals serve to transmit belief systems and norms of behaviour. ${ }^{84}$ The lack of such unifying practice can negatively influence the maturation process of an individual in the same way as, noted by Kuh et al, "poor family function may set a chain of adversity by inhibiting the acquisition of social capital-such as skills and self-esteem-which may lead to the possible presence of adolescent health complaints". ${ }^{33}$

The families of those youngsters who requested assistance from mental health centres practise fewer life cycle rituals than the comparison group. These rituals facilitate positive changes during the development of an individual and indicate 
important moments in a person's life. ${ }^{8}$ The lack of such practice can represent one more factor that impedes the resolution of the crisis of adolescence. ${ }^{33} 34$

Celebrations with the extended family, for example, are an important source of information providing family histories and modelling conflict resolution; stories of the parents as children, or how an uncle or grandfather may have overcome some particular difficulty. Depriving a child of such information, so crucial to the maturation process, puts the child at a disadvantage in formulating his/her own sense of self..$^{15} 30$

In contrast with the adolescents of the comparison group, the adolescents who sought assistance also practise less activities with their parents, such as travelling, talking and shopping together. It is interesting to observe that these kind of activities, which facilitate communication as well as emotional closeness, may play an important part in the future, allowing the families to implement the educational function and the emotional development of its members while theythe families-remain stable within a fluctuating society. ${ }^{3}$

Finally, the perception of the case group with respect to family function as manifested in the feeling of being loved, of spending time together, and of solving problems, is significantly more negative than in the comparison group. This completes the profile that differentiates the two groups based on their respective perceptions of family rituals, activities and function.

When the development of intervention strategies is the aim in public health, the study of settings and/or systems seems to be, at times, a very useful instrument in analysing health problems. In this sense, the theoretical principle of this paper is based on circular causality, on the idea that an individual influences and is influenced by the context in which the person lives, in this case, the family. Thus, a more thorough study identifying the parameters in the area of family relations would be necessary. In the meantime, gathering information on ritual and family activities could be included in interviews of professionals working with adolescents in the clinical field to identify the possible presence of social/family factors that influence the patient's condition.

\section{Authors' affiliations}

E Compañ, E Pascual, Health and Social Services of Alicante District, Spain

J Moreno, "La Florida" Health Centre, Valencian Health Services, Spain M T Ruiz, Public Health Department, University of Alicante, Spain

\section{REFERENCES}

1 Susser M. Does risk factors epidemiology put epidemiology at risk? Peering into the future. J Epidemiol Community Health 1998;52:608-11.

2 Bertalanfy LV. General system theory. New York: George Braziller, 1968

3 Salem G. L'aproache thérapeutique de la famille. Paris: Masson, 1990

4 Prigogine Y, Stengers Y. Entre le temps et l'eternité. Paris: Librairie Artheme Feyard, 1988.
5 Laszlo E. Evolution: the grand synthesis. New York: New Science Library, 1992

6 Ortega F. Le jeu et les règles. Thérapie Familiale 1994;15:339-47

7 Selvini M, Boscolo L, Cecchin G, et al. Family rituals: a powerful tool in family therapy. Family Process 1977;16:445-54.

8 Imber-Black E, Roberts J, Whiting R. Rituals in families and family therapy. Portland: Booknews, 1989

9 Wolin SJ, Bennet LA. Family rituals. Family Process 1984; 23: 401-420

10 Morval M, Biron G. Les rituels familiaux et leurs fonctions. Thèrapie Familiale 1993; 14:149-53.

11 Garberí R, Compañ E. Atrapados por el ritual a qué juegan las parejas? Alicante: Diputación Provincial, 1994

12 Rosenthal CJ, Marshall VW. Generational transmission of family ritual. Special issue: rituals and reunions. The American Behavioural Scientist 1988;31:669-84

13 Lackson S, Bijstra J, Oostra L. Adolescents' perceptions of communication with parents relative to specific aspects of relationships with parents and personal development. J Adolesc 1998:21:305-22.

14 Fiese BH. Dimensions of family rituals across two generations: relation to adolescent identity. Fam Process 1992;31:151-62.

15 Bennett LA, Wolin SJ, McAvity KJ. Family identity, ritual and myth: a cultural perspective on lifecycle transitions. In: Falicov CJ, ed. Family transitions. New York: The Guilford Press, 1988.

16 Fishman H. Treating troubled adolescents. A family therapy approach. New York: Basoc Books, 1988.

17 Sheeber L, Hops H, Alpert A. Family support and conflict: prospective relations to adolescent depression. J Abnorm Child Psychol 1997;25:333-44

18 Bowen M. Family therapy in clinical practice. New York: Janson Aronson, 1995

19 Hess LE. Changing family patterns in Western Europe: opportunity and risk factors for adolescent development. In: Rutter M, Smith DJ, eds. Psychosocial disorders in young people: time trends and their causes. Chichester: Wiley, 1995.

20 Kiernan KE. The impact of family disruption in childhood on transitions made in young adult life. Popul Stud 1992;46:213-34.

21 Vidovic V, Juresa V, Rudan V. The adolescents assessment of family functioning. Collegium Antropologicum 1997;21:269-76.

22 William B. The family physician's role in keeping parents involved in their adolescents' lives. Am Fam Physician 1995:2:106-8.

23 Revilla L, Aranda JM, Luna JD. Influencia de las variables sociodemográficas y de la cultura familiar en el uso de consultas médicas. Atención Primaria 1987;4:472.

24 Wolin SJ, Bennet LA, Noonan DL. Family rituals and the recurrence of alcoholism over generations. Am J Psychiatry 1979;136:589-93.

25 Fiese BH. Family rituals in alcoholic and non-alcoholic households: relations to adolescent health symptomatology and problem drinking. Family Relations 1993;42:187-92.

26 Revilla L. Conceptos e instrumentos de la atención familiar. Barcelona: Doyma, 1994.

27 Smilkstein G. Family APGAR analysed. Fam Med 1993;5:293-4

28 Rodriguez E, Gea A, Gómez A, et al. Estudio de la función familiar a través del cuestionario APGAR. Atención primaria 1996;17:22-36.

29 Bott E. Family and Social network. London: Tavistock Institute of Human Relation, 1971

30 Bowen M. Dalla famiglia all'individuo. La differenziazione del sé nel sistema familiare. Rome: Casa Editrice Astrolabio-Ubaldini ed 1991.

31 Goodrich Th, Rampage Ch, Ellman B, et al. Feminist family therapy. New York: WW Norton, 1988

32 Parsons T. The social structure of the family. New York: Anshen RN 1949.

33 Kuh D, Power Ch, Blane D, et al. Social pathways between childhood and adult health. In: Kuh D, Ben-Shlomo Y, eds. A life course approach to chronic disease epidemiology. London: Oxford University Press, 1997: 169-98

34 Levy SY, Wamboldt FS, Fiese BH. Family of origin experiences and conflict resolution behaviours of young adult dating couples. Fam Process 1997:36:297-31. 